\title{
A contribuição da biblioteca escolar na formação de leitores enfocando o desenvolvimento individual e organizacional
}

The school library contribution in the formation of readers focusing on the individual and organizational development

Elaine da Silva

Doutoranda e Mestre em Ciência da Informação pelo Programa de Pós-Graduação em Ciência da Informação na

Universidade Estadual Paulista "Júlio de Mesquita Filho" - UNESP, Câmpus de Marília.

E-mail: elainesilva2108@icloud.com

\section{Resumo}

Discute a importância da leitura e da formação de leitores para o desenvolvimento da sociedade, considerando que a leitura é elemento essencial na formação de cidadãos competentes em informação, capazes de posicionar-se com autonomia e criticidade diante de situações e perspectivas sociais. Nesse contexto analisa o papel das bibliotecas escolares posto que, muitas vezes, caracterizam a primeira instituição voltada à leitura a que muitos têm ou deveriam ter contato no início da formação escolar.

Palavras-chave: Formação de leitores. Biblioteca escolar. Leitura como elemento para o desenvolvimento social. Políticas públicas para o livro, leitura e biblioteca. Alfabetismo funcional.

\begin{abstract}
Discusses the importance of reading and reader's formation for the development of society, considering that reading is an essential element to prepare information literate citizens, able to position themselves with autonomy and criticality in situations and social perspectives. In this context, examines the role of school libraries, considering that often characterize the first institution focused on reading that many have or should have contact in scholar life.
\end{abstract}

Keywords: Reader's formation. School library. Reading with element for social development. Public policies for the book, reading and library. Functional literacy. 
A contribuição da biblioteca escolar na formação de leitores enfocando o desenvolvimento individual e organizacional

\section{Introdução}

A competência em leitura e da escrita foi sempre considerada um diferencial na sociedade, desde tempos mais longínquos quando apenas a alguns privilegiados era permitido acessar e decifrar os códigos que registravam o conhecimento. Eram os chamados escribas, que até o século XV foram responsáveis por registrar e, por consequência, perpetuar conhecimentos para as gerações futuras. Como não eram muitos e faziam uma cópia de cada vez, a produção dos escribas era pequena e tinha custos impeditivos para a maioria da população.

A prensa de Gutenberg, datada de 1455, trouxe a possibilidade de disseminar registros do conhecimento de maneira ampliada. Com o surgimento da imprensa o acesso aos livros impressos se expandiu e o livro deixou de ser objeto exclusivo de ambientes reais, clericais e acadêmicos; passando a ser encontrado sob a guarda de qualquer pessoa que manifestasse interesse e tivesse dinheiro para adquiri-lo.

No entanto, muito além de questões de ordem econômica, o acesso e a possibilidade de apropriação da informação, do conhecimento registrado nos livros, sempre esteve às bailas com o poder, a dominação e a subjugação, condição revelada na literatura e no cinema em diversas obras literárias e cinematográficas.

Mesmo na sociedade atual, chamada de sociedade da informação e do conhecimento, em que o acesso ao conhecimento registrado vem sendo grandemente facilitado por Tecnologias da Informação e Comunicação (TIC), ainda é possível verificar em países como o Brasil, que a grande parte da população não se constitui numa população de leitores. Isso implica inferir que a maioria das pessoas não se apropria das informações disponibilizadas e não constrói conhecimento tanto quanto poderia.

O presente artigo discute a importância da leitura e da formação de leitores para o desenvolvimento da sociedade, por meio de cidadãos competentes em informação, capazes de posicionarem-se com autonomia e criticidade diante de situações e perspectivas sociais. Nesse contexto, é analisado o papel das bibliotecas escolares posto que, muitas vezes, caracterizam a primeira instituição voltada à leitura a que muitos têm ou deveriam ter contato no início da formação escolar. 
As reflexões que se apresentam constituem o fruto de uma pesquisa bibliográfica acerca dos temas: a importância e a influência da leitura para o desenvolvimento social retratadas em clássicos da literatura e do cinema e; o papel da biblioteca escolar na formação de leitores.

\section{O poder da informação retratado nas artes}

A vulnerabilidade de quem não é capaz de ler e escrever é retratada o filme brasileiro Central do Brasil ${ }^{1}$, dirigido por Walter Sales que se inicia com a atuação de uma 'escrevedora de cartas', como é chamada uma das personagens centrais da trama, uma professora aposentada que trabalha na maior estação de trem da cidade do Rio de Janeiro escrevendo cartas para pessoas que não têm essa competência. O filme, produzido no ano de 1998 e ambientado no mesmo período, faz pensar no quanto pode ser limitador não ser competente em leitura e escrita. O que diferencia a personagem não é nenhum recurso material, como uma máquina de escrever ou tinta e papel, mas sim a possibilidade de transformar os sentimentos, anseios e credos explicitados oralmente por alguém em signos que, colocados num pedaço de papel podem chegar a um destinatário distante e, quiçá, mudar o destino dos envolvidos.

Certamente não se pode reduzir a sabedoria ou a inteligência de uma pessoa à sua competência para ler e escrever mas, é possível crer que ampliar as possibilidades de leitura, e leitura aqui compreendida em seu sentido amplo - leitura de textos, de imagens fixas, de imagens em movimento, do som (inclusive da oralidade) - permite àquele que se apropria do que lê, ampliar seu acervo de conhecimento e, por conseguinte, poder atuar criticamente na sociedade em que vive.

Esse seguramente é o temor representado em 'Fahrenheit 451'2; a obra literária americana de Ray Bradbury que teve sua adaptação para o cinema dirigida por François Truffaut em 1966 apresenta uma sociedade futura, na qual os livros são considerados maléficos para a sociedade pois, segundo o regime totalitário em que a obra é ambientada, a leitura propicia o conhecimento e o pensamento crítico, condenáveis por tornar as pessoas infelizes e improdutivas. Ora, se as pessoas nada conhecem ou imaginam além daquilo que lhes é apresentado como verdade absoluta, certamente não anseiam por nada além do 'existente', por

\footnotetext{
${ }^{1}$ CENTRAL do Brasil. Direção de Walter Salles Júnior. Produção: Martire de Clemont-Tonnerre e Artur Cohn. [S.1.]: Le Studio Canal; Riofilme; MACT Productions, 1988.

${ }^{2}$ BRADBURY, R. Fahrenheit 451: a temperatura na qual o papel do livro pega fogo e queima. São Paulo: Melhoramentos, 2003.
} 
A contribuição da biblioteca escolar na formação de leitores enfocando o desenvolvimento individual e organizacional

consequência devem ser felizes, pois nada mais podem almejar, nem para si, nem para o outro, nem para a sociedade, nem para o futuro.

Um regime totalitário e controlador de quais informações as pessoas poderiam ter acesso e possivelmente apropriarem-se é relatado no clássico da literatura inglesa ' 1984 ' de George Orwell publicado em 1949. Personagem central e de certa forma abstrato, o Grande Irmão vê tudo e controla tudo, inclusive a história: qualquer fato que pudesse suscitar ou despertar críticas deveria ser reescrito, de forma a confirmar o regime, que tinha como lemas: 'Liberdade é escravidão; Ignorância é força; Guerra é paz'. Controlada toda e qualquer possibilidade de informação, poderia também o pensamento do indivíduo ser controlado pelo Grande Irmão.

Os exemplos evidenciam o quanto a ignorância pode ser útil àqueles que pretendem manipular e dominar outros indivíduos e, o quanto a ausência de informação ou a (des)informação facilitam a aceitação da ordem e da verdade que se apresentam.

A não aceitação da realidade apresentada como única, verdadeira e boa, é retratada no clássico 'Madame Bovary' ${ }^{4}$ do francês Gustave Flaubert, publicado originalmente em 1856. O autor retrata de maneira primorosa o quanto a leitura pode levar aquele que a pratica e das informações se apropria, a questionar e a não aceitar a 'realidade' que lhe é apresentada. $\mathrm{O}$ hábito da leitura fazia com que a personagem central da obra ansiasse por conhecer diferentes lugares, diferentes pessoas, diferentes amores, diferentes formas de viver.

\section{A leitura como caminho para apropriação da informação}

A leitura (de textos, de imagens fixas, de imagens em movimento, de sons) apresentase como um caminho possível para a apropriação da informação, que poderá levar o leitor a construir, ao longo da vida, seu acervo de conhecimento; que influenciará suas atitudes, escolhas e tomadas de decisão, em âmbitos pessoal, profissional e social.

É seguro afirmar que a leitura é fundamental para o desenvolvimento dos indivíduos, das organizações e das nações pois, a leitura pode levar à apropriação da informação, que pode levar à construção do conhecimento, que pode levar ao desenvolvimento individual, organizacional e social.

\footnotetext{
${ }^{3}$ ORWELL, G. 1984. São Paulo: Companhia das Letras, 2009.

${ }^{4}$ FLAUBERT, G. Madame Bovary. Belo Horizonte: Itatiaia, 2009.
}

Bibl. Esc. em R., Ribeirão Preto, v. 3, n. 2, p. 15-30, 2015. 
Toda a trajetória de construção do conhecimento iniciada com a leitura, também pode levar o sujeito a descobrir diferentes realidades, diferentes caminhos, diferentes possibilidades e, assim como Madame Bovary não mais se satisfazer com o que lhe é apresentado como único caminho possível. O sujeito cognoscente, que se constrói a partir do processo da leitura, apropriação da informação e construção do conhecimento é um sujeito autônomo, crítico e dificilmente manipulável; portanto, muito diferente dos cidadãos retratados nas obras 'Fahrenheit 451' e '1984'.

Na sociedade atual, a partir do advento das TIC, em especial o surgimento da internet, um novo grande salto é conquistado no que tange à disponibilização do conhecimento registrado e disponibilizado para a leitura. Diferente do registro em papel possibilitado pela prensa de Gutenberg, que requeria um processo razoavelmente longo de processamento e distribuição, a grande rede de computadores permite acesso instantâneo a todo o conhecimento registrado e nela disponibilizado simultaneamente a um incontável número de pessoas e, segundo os organizadores de conteúdo, muitas vezes gratuitamente; tudo que se precisa é possuir o acesso ao equipamento, à internet e a competência para usá-los.

De fato, com relação à disponibilização de conhecimento externalizado, codificado e registrado observa-se uma grande evolução, em especial em termos quantitativos. Certamente seria necessário aos bombeiros de 'Fahrenheit 451' o desenvolvimento de novas técnicas de trabalho para alcançar o objetivo de impedir as pessoas de acessarem os registros do conhecimento humano.

Entretanto, se por um lado há uma oferta muito maior e mais dinâmica dos registros do conhecimento, não é possível afirmar que essa progressão se dê também no aumento de sujeitos cognoscentes, autônomos e críticos, prontos a contribuir para a construção de novos conhecimentos e para o desenvolvimento social, econômico e político da sociedade da qual participam. 
A contribuição da biblioteca escolar na formação de leitores enfocando o desenvolvimento individual e organizacional

\section{A sociedade da informação e do conhecimento e a formação de leitores}

Muito se discute em diferentes fóruns sobre a chamada sociedade da informação e do conhecimento, caracterizada pela centralidade dos elementos informação e conhecimento em transações econômicas, fabris, comerciais etc. Diferente da sociedade industrial, marcada pela centralidade da industrialização e de recursos materiais, na sociedade da informação e do conhecimento os recursos mais valiosos são intangíveis, imateriais. Assim, o valor de uma empresa não é calculado apenas a partir do valor de suas instalações físicas (imóveis, móveis, equipamentos), devem ser considerados também os elementos imateriais, como marca, credibilidade, capacidade de adaptação às flutuações de mercado e capacidade inovativa. É possível afirmar que todas as características reconhecidas como centrais para o desenvolvimento organizacional na atualidade, pautam-se em informação e conhecimento, elementos imateriais que só existem pela ação do sujeito cognoscente.

Porquanto, um grande desafio para a atual sociedade da informação e do conhecimento reside no reconhecimento da importância da leitura, da apropriação da informação e da construção do conhecimento como fatores fundamentais para o desenvolvimento de cidadãos autônomos e críticos que possam contribuir de maneira efetiva para o desenvolvimento nos contextos organizacionais, sociais e políticos em que se inserem.

Nesse sentido e considerando a realidade brasileira, em especial no que tange à competência em leitura, cumpre destacar que a nação ainda enfrenta um panorama nada animador referente à alfabetização. Segundo a última edição do Indicador de Alfabetismo Funcional (INAF) o país teria, em 2012, apenas 26\% da população entre 15 (quinze) e 64 (sessenta e quatro) anos de idade plenamente alfabetizada (INSTITUTO..., [2011]). Segundo o INAF, é considerada plenamente alfabetizada a pessoa que não apresenta restrições para compreender e interpretar textos longos. Os $74 \%$ da população brasileira não plenamente alfabetizada, segundo o INAF, estariam assim distribuídos:

- $47 \%$ - Alfabetizado básico: lê e compreende textos médios;

- $21 \%$ - Alfabetizado rudimentar: localiza uma informação explícita em textos curtos e familiares;

- $06 \%$ - Analfabeto: não realiza tarefas que envolvam leitura.

A incapacidade de compreender e interpretar um texto pode resultar numa sociedade de sujeitos manipuláveis e acríticos tanto quanto eram os moradores da fictícia Oceania do livro 
'1984'. Isso permite inferir que grande parte da nossa população não é impedida de se apropriar da informação porque livros não são acessíveis ou são queimados, mas porque são incapazes de compreendê-los e interpretá-los, mesmo que tenham frequentado a escola por alguns anos.

Os motivos pelos quais uma pessoa permanece 'basicamente alfabetizada', ou seja, incapaz de compreender e interpretar textos longos independente da escolarização são, certamente, vários e complexos. Sem a pretensão de esgotar o tema, mas destacar possíveis fatores de ordem social, poderíamos citar: subnutrição; acometimentos na saúde oriundos de problemas sanitários e deficiências no sistema de educação pública, todos relevantes e merecedores de atenção. Entretanto, acredita-se que um outro aspecto, também social mas que não se vincula diretamente à condição econômica possa influenciar na permanência de indivíduos na condição de basicamente alfabetizados, trata-se da superficialidade.

A superficialidade pode ser entendida como uma consequência da sociedade atual, caracterizada por muita produção e disponibilização de informação, acesso facilitado e um grande número de pessoas não plenamente alfabetizadas. Esses fatores juntos podem levar a um cenário em que as pessoas leem, mas muitas vezes não com a profundidade necessária para que de fato possam compreender, interpretar e gerar conhecimento.

O advento das TIC permitiu a possibilidade de conectividade constante, assim, é possível receber e responder e-mails, utilizar redes sociais, fazer buscas na internet ou comentar sobre um acontecimento (político, social, meteorológico, gastronômico etc.) a qualquer hora, em qualquer lugar e tendo um número infinito de interlocutores.

A agilidade promovida pela conectividade trouxe consigo um sentimento de urgência nem sempre necessário que pode levar à superficialidade. Assim, mesmo sem checar a veracidade, sem consultar fontes confiáveis para confirmação, mensagens de ordem diversas são compartilhadas como verdadeiras. Textos são enviados para as redes de contato antes mesmo que o remetente tenha finalizado a leitura. Opiniões e comentários são emitidos apenas pela leitura do título ou do primeiro parágrafo e sem reflexão. Enquanto isso, tantas outras mensagens, textos, comentários, e-mails, jogos, lembretes, vídeos, animações etc. estão saltando nas telas de diferentes dispositivos implorando por atenção.

Nesse contexto, um grande número de pessoas se abstém da atividade de leitura como meio para a apropriação da informação e geração de conhecimento e seguem lendo apenas pequenos textos que não apresentam nenhum grau de complexidade. Entretanto, tal fato não se 
A contribuição da biblioteca escolar na formação de leitores enfocando o desenvolvimento individual e organizacional

deve a motivos de saúde ou econômicos, mas sim ao sentimento de urgência que invade o diaa-dia e faz com que tudo seja lido com superficialidade, primeiro porque há 'tanta coisa ainda por ler' e, segundo, porque 'tudo está acessível na rede', caso seja necessário reler. Caber ressaltar que não são as TIC que produzem a superficialidade, mas sim o comportamento dos sujeitos cognoscentes diante desse novo paradigma.

Enfim, apresenta-se um contexto em que, embora a quantidade e o acesso ao conhecimento registrado seja cada vez maior e mais facilitado, cada vez menos as pessoas se entregam à leitura, se apropriam de informações e constroem conhecimento. Isso implica inferir que, os sujeitos cognoscentes, críticos, com autonomia para propor inovações, participar efetivamente para o desenvolvimento das organizações em que estão inseridos, estejam, talvez, desaparecendo, a exemplo dos clássicos da literatura '1984' e 'Fahrenheit 451'.

Porquanto, julga-se pertinente que instituições voltadas à leitura, à informação e ao conhecimento estejam atentas e busquem o quanto possível enfocar não apenas o acesso à informação e aos documentos, mas também a formação de leitores autônomos, críticos e participantes ativos na sociedade. Entende-se que, dentre tantas instituições voltadas à leitura, informação e conhecimento, seja a biblioteca escolar merecedora de especial atenção por caracterizar, em muitos casos, a primeira organização oficialmente instituída para esse fim com que o sujeito cognoscente, no caso a criança, tem contato. 


\section{A formação de leitores no contexto da biblioteca escolar}

A partir do surgimento e da popularização da imprensa e posteriormente da internet, não há dúvida de que a cada dia mais conhecimento é registrado e mais informação torna-se acessível. Entretanto não pode ser observada uma progressão diretamente proporcional no que tange à quantidade de pessoas plenamente alfabetizadas e competentes para se apropriar da informação disponibilizada enfocando o desenvolvimento pessoal e social. Nesse contexto, acredita-se que seja necessário refletir sobre a formação do leitor.

O ideal é que a formação do leitor se inicie no ambiente familiar; entretanto, por condições e situações diversas nem sempre o ideal se faz possível. Por consequência, a escola é muitas vezes o ambiente que assume a responsabilidade de apresentar às crianças o universo da leitura e, nesse contexto, a biblioteca escolar deve ter papel fundamental. De acordo com a IFLA e a Unesco a biblioteca escolar deve ser parte integral do processo educativo e enfocar os seguintes objetivos:

- apoiar e intensificar a consecução dos objetivos educacionais definidos na missão e no currículo da escola;

- desenvolver e manter nas crianças o hábito e o prazer da leitura e da aprendizagem, bem como o uso dos recursos da biblioteca ao longo da vida;

- oferecer oportunidades de vivências destinadas à produção e uso da informação voltada ao conhecimento, à compreensão, imaginação e ao entretenimento;

- apoiar todos os estudantes na aprendizagem e prática de habilidades para avaliar e usar a informação, em suas variadas formas, suportes ou meios, incluindo a sensibilidade para utilizar adequadamente as formas de comunicação com a comunidade onde estão inseridos;

- prover acesso em nível local, regional, nacional e global aos recursos existentes e às oportunidades que expõem os aprendizes a diversas ideias, experiências e opiniões;

- organizar atividades que incentivem a tomada de consciência cultural e social, bem como de sensibilidade;

- trabalhar em conjunto com estudantes, professores, administradores e pais, para o alcance final da missão e objetivos da escola;

- proclamar o conceito de que a liberdade intelectual e o acesso à informação são pontos fundamentais à formação de cidadania responsável e ao exercício da democracia;

- promover leitura, recursos e serviços da biblioteca escolar junto à comunidade escolar e ao seu derredor (MANIFESTO..., 1999, p. 2-3).

Levar a comunidade escolar à prática e ao gosto pela leitura de maneira integrada aos fazeres da escola, promovendo a formação de indivíduos autônomos e competentes em informação é, portanto, foco da atuação da biblioteca escolar, que deve buscar contribuir efetivamente para a formação de leitores de fato, capazes de se apropriar das informações contidas em diferentes suportes enfocando a construção do conhecimento. No entanto, embora 
A contribuição da biblioteca escolar na formação de leitores enfocando o desenvolvimento individual e organizacional

constitua um elemento reconhecidamente importante na formação de leitores, a biblioteca escolar ainda encontra dificuldade em cumprir esse papel.

\begin{abstract}
Se por um lado, existe a necessidade de garantir o acesso e a fruição às diferentes formas literárias produzidas historicamente pelo homem e, por outro, um crescente movimento de composição desses acervos escolares para instrumentar o trabalho pedagógico com livros literários, várias pesquisas e avaliações de caráter nacional e internacional têm demonstrado, no entanto, que ainda encontramos dificuldade de formar leitores na escola (SANTOS; SOUZA, 2009, p. 98).
\end{abstract}

Diante de tal perspectiva, se faz necessário refletir sobre a constituição e atuação das bibliotecas escolares e dos profissionais que nela atuam. Nesse contexto, destaca-se a contribuição de Bicheri e Almeida Jr. (2013, p. 43) ao postularem que

\begin{abstract}
A simples existência de uma biblioteca escolar, bem localizada, de bom tamanho, bem decorada, com um grande acervo atualizado não é suficiente para atender as necessidades da comunidade escolar e contribuir para a qualidade do ensino e formação do aluno.

Para que a biblioteca escolar possa cumprir com seu papel é necessário, além de espaço e acervo, de um bibliotecário competente e engajado na escola como um todo. Importa, e muito, a qualidade das atividades, as atitudes tomadas pelo bibliotecário, que deve ser competente, comunicativo, interessado e criativo.
\end{abstract}

Certamente é preciso que hajam espaços dentro do ambiente escolar destinados a bibliotecas. É importante que sejam espaços confortáveis, com ventilação e iluminação adequadas, com decoração e mobiliário apropriados de modo a tornar o espaço convidativo e prazeroso. Entretanto, apenas a constituição física/ predial não é suficiente. Mais que um espaço fisicamente adequado, deve ser a biblioteca escolar um espaço voltado para a formação de leitores, que prime pela "independência e autonomia na leitura, favorecendo a parceria de professor e bibliotecário" (BICHERI; ALMEIDA JR., 2013, p. 42). Porquanto, cabe ao bibliotecário identificar necessidades e expectativas informacionais de seu público e, para isso precisa estar inserido aos processos escolares de maneira ativa, inclusive participar da elaboração do projeto pedagógico da escola, o qual deve contemplar a biblioteca como um ambiente dinâmico de ensino-aprendizagem.

Sabidamente atividades como seleção, organização e disponibilização de acervo adequado ao público são essenciais para uma biblioteca escolar; assim como atividades relacionadas com a prática da leitura. Entretanto para que se obtenha êxito na formação de leitores é também importante que o bibliotecário escolar esteja consciente quanto ao seu real papel no contexto escolar no que tange à formação de leitores e transformação social. Bicheri e Almeida Júnior ressaltam que cabe ao profissional bibliotecário escolar: 
Questionar-se, conhecer sua área de atuação, ter a satisfação do usuário como fim, lidar com informações que não são neutras e imparciais, colaborando para a formação do cidadão realmente são atitudes que fazem do bibliotecário escolar um importante agente de transformação social.

O bibliotecário escolar, como mediador, deve estar inserido na comunidade escolar, conhecer e participar das propostas curriculares e fazer da biblioteca um espaço integrado a escola, proporcionando momentos de descoberta, alegria, criatividade, reflexões, debates, questionamentos, aprendizagem e prazer, entre outros (2013, p. 47).

Ao enfocar a formação de leitores com vistas à diminuição da superficialidade na leitura, cumpre alertar que "as experiências literárias e a formação da sensibilidade linguística devem ser privilegiadas em um trabalho a ser desenvolvido na biblioteca escolar" (SANTOS; SOUZA, 2009, p. 100). Autores como Santos e Souza (2009) e Bicheri e Almeida Júnior (2013) destacam que além de atividades corriqueiras como hora do conto; consulta ao acervo; empréstimos domiciliares e leitura livre, a biblioteca escolar deve desenvolver outras formas de práticas de leitura, tais como: saraus literários; leituras em grupo; rodas de discussão, comentários e recomendações de leituras realizadas; entrevistas com autores (presenciais ou com o intermédio de mídias diversas); projeções de filmes relacionados a livros lidos e posterior seção de debates; concursos literários; feiras de livros e varais de poesias entre outras práticas possíveis. Para além da atividade em si, ressalta-se a importância das chamadas práticas de leitura, pois

\footnotetext{
Na verdade ela, a contribuição, está nas "entrelinhas" da mediação, da intervenção deste profissional na escola, no seu engajamento e comunicação na comunidade, como trabalha em parceria, sua maneira de organizar o espaço da biblioteca (organização do ambiente e tempo para frequência e leitura), ao receber seus usuários, na demonstração do amor pela leitura, na indicação de leituras, na forma em que lê uma história, como conta uma história e a escuta, ao apresentar um autor e se apresentar como bibliotecário leitor, não desistindo frente às dificuldades encontradas e criando oportunidades de leitura frente à vida escolar (BICHERI; ALMEIDA JÚNIOR , 2013, p. 52).
} 
A contribuição da biblioteca escolar na formação de leitores enfocando o desenvolvimento individual e organizacional

\title{
A biblioteca escolar no Brasil e políticas públicas relacionadas
}

A realidade brasileira não apresenta um contexto satisfatório e animador quando o assunto são bibliotecas escolares. Dados do portal QEdu indicam que o Censo Escolar/INEP 2013 apontou a presença de bibliotecas em apenas 35\% das escolas das redes pública e privada, correspondendo a 66.745 escolas de um total de 190.706 em todo o território nacional (MATRÍCULAS..., 2013).

De acordo com Almeida Júnior as bibliotecas não são consideradas prioridade nem mesmo na concepção e planejamento de unidades escolares. O autor destaca que "muitas escolas têm seu funcionamento aprovado e iniciado sem um espaço para a biblioteca" (2012, p. 19), o autor alerta ainda que, além da ausência na grande maioria das escolas do país,

\begin{abstract}
A biblioteca escolar, quando existe, é também utilizada como local de castigo, de cumprimento de sanções. $\mathrm{O}$ aluno com um comportamento considerado inadequado pelo professor e pela direção da instituição de ensino é enviado - acredito que com menor frequência do que há algum tempo - para a biblioteca. É impossível acreditar que a imagem da biblioteca para o aluno a que ela foi encaminhado para cumprir um castigo, possa ser a de um local agradável, prazeroso, encantador, simpático. [...] Os profissionais que nela atuam, terão suas imagens relacionadas, provavelmente, a carrascos, pois são eles os "executores", os supervisores dos castigos (ALMEIDA JÚNIOR, 2012, p. 19).
\end{abstract}

Na mesma direção, Silva e Siqueira (2014) acreditam que as atividades desenvolvidas em bibliotecas escolares devam ser cuidadosamente planejadas e desenvolvidas a fim de que possam contribuir efetivamente para a formação de leitores na escola.

[...] a simples existência dessas bibliotecas não basta para que as suas funções elementares sejam cumpridas. São necessários programas e procedimentos que se somem aos processos vigentes de educação. Ou seja, um plano de trabalho a partir do qual o bibliotecário articule o know-how informativo com as competências exigidas da comunidade escolar, dentre as quais, atividades de alfabetização e inclusão digital. (SILVA, SIQUEIRA, 2014, p. 39-40)

Corroborando com a percepção de que a biblioteca ainda é mal interpretada e subutilizada no país, Silva (2012, p. 157-158) afirma que

\footnotetext{
Em nosso sistema educacional a biblioteca escolar ainda precisa ser compreendida em toda a sua potencialidade no processo ensino-aprendizagem, ou seja, como um dos principais veículos de formação de leitores, pesquisadores e cidadãos mais conscientes de seu papel humano e social.

Nesse contexto, formar leitores é uma das possibilidades de o Brasil continuar a crescer, não só tecnologicamente ou educacionalmente, mas também em relação ao seu futuro, para a prosperidade do país.
}

Acredita-se que tal situação, reveladora de um panorama em que a biblioteca escolar não é entendida como um centro de acesso e apropriação da informação e de construção do 
conhecimento, seja acentuada por políticas públicas relacionadas a bibliotecas escolares que preocupam-se tão somente com a distribuição de livros às escolas. Um exemplo, é a Resolução n 7 de 20 de março de 2009, do Fundo Nacional de Desenvolvimento da Educação, órgão do Ministério da Educação que estabelece o

[...] Programa Nacional Biblioteca da Escola (PNBE), para prover as escolas de ensino público das redes federal, estaduais, municipais e do Distrito Federal, no âmbito da educação infantil (creches e pré-escolas), do ensino fundamental, do ensino médio e da educação de jovens e adultos (EJA), com o fornecimento de obras e demais materiais de apoio à prática da educação básica, de acordo com o Anexo desta Resolução. (BRASIL, 2009, p. 01)

Obviamente a seleção e distribuição de livros às escolas são fundamentais, entretanto, um programa de âmbito nacional dedicado às bibliotecas escolares não pode limitar-se a isso. Atividades de seleção e distribuição podem representar um primeiro passo, todavia cumpre lembrar que o acesso aos livros não garante a formação leitores.

Um outro exemplo no âmbito de políticas públicas relacionadas à formação de leitores é o Plano Nacional do Livro e Leitura (PNLL), instituído em 2006 pelos ministérios da Cultura e da Educação (PLANO..., 2010) que tem como pilares quatro eixos estratégicos:

1. Democratização do acesso;

2. Fomento à leitura e à formação de mediadores;

3. Valorização da leitura e comunicação;

4. Desenvolvimento da economia do livro.

Acredita-se que as diretrizes e linhas de ação traçadas pelo PNLL, se de fato implementadas, podem trazer valiosas contribuições no que tange a criação de mais e melhores bibliotecas pelo país que possam enfocar a formação de leitores. Nesse sentido, um grande avanço é apresentado pela Lei 12.244, de 24 de maio de 2010 (BRASIL, 2010), que determina a universalização das bibliotecas nas instituições de ensino no país, e prevê que seja respeitada a prerrogativa de atuação conferida a profissionais bibliotecários. Entretanto, cumpre destacar que a existência de políticas voltadas ao livro e à leitura não são um privilégio das últimas décadas, quando se sabe que 
A contribuição da biblioteca escolar na formação de leitores enfocando o desenvolvimento individual e organizacional

Em pleno governo ditatorial de Getúlio Vargas, por meio do Decreto-lei n. 93, de 21 de dezembro de 1937, criou-se o Instituto Nacional do Livro (INL), [...] com as seguintes competências: organizar e publicar a Enciclopédia Brasileira e o Dicionário da Língua Nacional, editar obras de interesse para a cultura nacional, criar bibliotecas públicas e estimular o mercado editorial mediante promoção de medidas para aumentar, melhorar e baratear a edição de livros no país (OLIVEIRA, 1994 apud ROSA; ODDONE, 2006, p. 186)

É evidente a relevância da implantação efetiva e a ampliação das diretrizes contempladas nas políticas públicas ligadas a bibliotecas, ao livro e à leitura e, em especial, à formação de leitores. Da mesma maneira, é importante que todos os atores envolvidos com a promoção da leitura, principalmente bibliotecários e professores, planejem e desenvolvam suas atuações enfocando a criação de uma imagem positiva da biblioteca escolar, além de envidar esforços para que a universalização das bibliotecas nos ambientes escolares seja de fato uma realidade até 2020.

\section{Considerações}

A biblioteca escolar, como explicitado, pode e deve atuar significativamente na formação de leitores junto aos cidadãos brasileiros em idade escolar. Entretanto dois fatores precisam ser considerados: no Brasil a existência de bibliotecas nos ambientes escolares ainda não é uma realidade para a maioria das escolas e, quando presentes, nem sempre as bibliotecas escolares são efetivamente integradas aos processos de aprendizagem ou atuam enfocando a formação de leitores e, por consequência, muitas vezes não são vistas como espaço de construção do conhecimento.

O panorama apresentado leva a inferir que as bibliotecas escolares não estão preparadas para alcançar todos os objetivos traçados pelo "Manifesto IFLA/UNESCO para biblioteca escolar" e anteriormente apresentados, por conseguinte não estão contribuindo efetivamente para a diminuição do percentual de pessoas analfabetas, rudimentarmente alfabetizadas e basicamente alfabetizadas no país. Acredita-se que esse fator tenha relação direta com o fenômeno da superficialidade na leitura. Nessa perspectiva, as pessoas mantêm a superficialidade em suas atividades de leitura porque não são competentes para ler, compreender e interpretar textos mais complexos.

Uma sociedade na qual as possibilidades de acesso à informação vêm se ampliando mais e mais a cada momento e, a leitura é praticada de maneira superficial por sujeitos que muitas 
vezes não compreendem, não questionam e não interpretam o que leem é, sem dúvida, um paradoxo que exige reflexão.

Se é verdade que a vida imita a arte, é melhor que tenhamos mais 'Madames Bovarys' a ler, sonhar, ousar e buscar possibilidades diferentes, do que cidadãos de '1984' e 'Fahrenheit 451' que, longe da leitura, da apropriação da informação e da construção do conhecimento seguem simplesmente aceitando o que lhes é dado como verdade.

É preciso que as bibliotecas escolares tenham consciência, condições, preparo e apoio para assumir seu real papel no que tange a formação de leitores na atual sociedade da informação e do conhecimento e, consequentemente, no alcance de melhores resultados em indicadores de alfabetização, que indicam a quantidade de indivíduos plenamente alfabetizados, capazes de ler, interpretar e construir conhecimento na sociedade em que estão inseridos; revelando-se cidadãos autônomos, críticos e responsáveis pelo desenvolvimento da sociedade.

\section{Referências}

ALMEIDA JÚNIOR., O. F. Espaços e equipamentos informacionais. In: BARBALHO, C. R. S. et al. Espaços e ambientes para leitura e informação. Londrina: ABECIN, 2012.

BICHERI, A. L. A. O.; ALMEIDA JÚNIOR, O. F. Bibliotecário escolar: um mediador de leitura. Biblioteca Escolar em Revista, Ribeirão Preto, v. 2, n. 1, p. 41-54, 2013. Disponível em: 〈http://revistas.ffclrp.usp.br/BEREV/article/viewFile/257/pdf>. Acesso em: 12 nov. 2014.

BRASIL. Ministério da Educação. Fundo Nacional de Desenvolvimento da Educação. Resolução no. 7, de 20 de março de 2009. Disponível em: <https://www.fnde.gov.br/fndelegis/action/UrlPublicasAction.php>. Acesso em: 18 nov. 2014.

BRASIL. Lei 12.244 de 24 de maio de 2010. Disponível em: <http://www.planalto.gov.br/ccivil_03/_Ato2007-2010/2010/Lei/L12244.htm>. Acesso em 19 nov. 2104.

INSTITUTO Paulo Montenegro. INAF Brasil 2011: Indicador de alfabetismo funcional: principais resultados. São Paulo: Instituto Paulo Montenegro, Ação Educativa, [2011]. Disponível em: <http://www.ipm.org.br/ipmb_pagina.php?mpg=4.02.01.00.00\&ver=por>. Acesso em: 16 jun. 2014.

MANIFESTO IFLA/UNESCO para biblioteca escolar. IFLA/UNESCO, 1999. Disponível em: 〈http://archive.ifla.org/VII/s11/pubs/portuguese-brazil.pdf〉. Acesso em 15 nov. 2014. 
A contribuição da biblioteca escolar na formação de leitores enfocando o desenvolvimento individual e organizacional

MATRÍCULAS e Infraestrutura. [S.1.: s.n.], 2013. Disponível em:

$<$ http://www.qedu.org.br/brasil/censo_escolar?year=2013\&dependence=0\&localization=0\&it em=>. Acesso em: 18 nov. 2014.

PLANO Nacional do Livro e Leitura. MINC; MEC, 2010.

ROSA, F. G. M. G.; ODDONE, N. Políticas públicas para o livro, leitura e biblioteca. Ciência da Informação, Brasília, v. 35, n. 3, p. 183-193, 2006. Disponível em: $<$ http://revista.ibict.br/cienciadainformacao/index.php/ciinf/article/view/814/656>. Acesso em: 19 nov. 2014.

SANTOS, C. C. S.; SOUZA, R. J. Programas de leitura em biblioteca escolar: a literatura a serviço da formação de leitores. In: SOUZA, R. J. Biblioteca escolar e práticas e educativas: o mediador em formação. Campinas: Mercado das Letras, 2009, p. 97-114.

SILVA, J. F. M.; SIQUEIRA, I. Biblioteca escolar como uma questão de direitos humanos. Biblioteca Escolar em Revista, Ribeirão Preto, v. 3, n. 1, p. 38-50, 2014. Disponível em: <http://revistas.ffclrp.usp.br/BEREV/article/view/326/pdf>. Acesso em: 17 nov. 2014.

SILVA, R. J. Projetar a biblioteca da escola: recomendações. In: BARBALHO, C. R. S. et al. Espaços e ambientes para leitura e informação. Londrina: ABECIN, 2012. 